\title{
EL HUMANISMO, REVOLUCIÓN CULTURAL
}

Jacques Lafaye*

RESUMEN: El movimiento humanista nacido en la Italia del siglo XIV y expandido por Europa en el XVI fue la primer revolución cultural moderna: una innovación pedagógica radical, sumada a cierta conjunción de circunstancias, que se concretó con la fundación de Colegios trilingües, dio lugar a una poderosa fuerza espiritual superior llamada Humanismo, que ciertamente parece en el peligro de extinción.

গ০e

\section{HuMANiSM: CUltural REVOLUTION}

ABSTRACT: Dating back to 14th century Italy, the humanism movement spread throughout Europe in the sixteenth century producing its first modern cultural revolution. The latter consisted of a radical pedagogical innovation resulting in the foundation of trilingual schools as well as the birth of a superior higher spiritual force, humanism, which nowadays seems to be in danger of extinction.

PALABRAS CLAVE: Humanismo, Renacimiento, revolución cultural, Colegios trilingües, traducción. KEY WORDS: Humanism, Renaissance, Cultural Revolution, trilingual schools, translation.

RECEPCIÓN: 18 de julio de 2014.

APROBACIÓN: 11 de agosto de 2014.

*El Colegio de Jalisco. 
CITAM Derechos Reservados.

La reproducción total o parcial de este artículo se podrá hacer si el ITAM otorga la autorización previamente por escrito. 


\section{EL HUMANISMO, REVOLUCIÓN CULTURAL}

\section{El humanismo ha sido la primera revo-} lución cultural moderna. Las revoluciones culturales no pueden resultar sólo de un plan preconcebido por una minoría selecta; son efecto de la conjunción de circunstancias sociales, económicas y políticas. Las culturas en general presentan una gran inercia; es una característica de la cultura judeocristiana de Occidente el haber generado varias rupturas culturales, calificadas modernamente como de vanguardia. Ahora, pensar en términos de vanguardias supone la fe en el mito del Progreso. El movimiento humanista, nacido en la Italia del siglo XIV y expandido en la mayor parte de Europa en el XVI, ha sido una "primavera" anterior en más de tres siglos a las místicas revolucionarias ilustradas o progresistas. En su forma original, el Humanismo se ha manifestado como innovación pedagógica radical: a los debates de la escolástica y sus silogismos se han sustituido la lectura y el comentario de textos humanísticos. Por humanístico se ha de entender el interés por las "letras humanas" (litterae humaniores), griegas y latinas antiguas, ajenas y en cierta medida opuestas a las "sagradas letras". Viene a decir en términos modernos que el humanismo fue una laicización de la cultura (por cultura se entiende, en este caso, lo que también se suele calificar como “alta cultura"). De gran significado ha sido la humanización de la interpretación de la historia por los florentinos Maquiavelo y Guicciardini, al hacer caso omiso de la providencia divina. No obstante, sería un ana- 
cronismo confundir el humanismo renacentista con el racionalismo radical que provocó, al final del siglo XIX y principios del XX, el Kulturkampf en Alemania y la lucha por la Laïcité de la educación en Francia. Excusado es decir que el movimiento humanista no fue un fenómeno "de masas", por dos razones: no había masas alfabetizadas en la Europa de aquel tiempo, y el poder de la Iglesia era preeminente pues la fe popular estaba muy arraigada. El humanismo fue un fenómeno minoritario y elitista, pero no menos trascendente: si las estadísticas miden la economía, no son tan pertinentes para estimar las coyunturas culturales.

La conjunción de circunstancias y evoluciones que hicieron posible el surgimiento y la rápida expansión del humanismo es de carácter muy heterogéneo. Se han señalado tradicionalmente la caída de Constantinopla (1453) y el subsiguiente éxodo de sabios bizantinos, esto es helenistas, a Italia. Si bien esto es cierto, hace falta recordar que la migración de élites intelectuales procedentes de Bizancio y el Despotado de Morea se inició antes de 1453 . Hubo otra causa que merece destacarse: es el florecimiento económico de ciudades italianas como Roma, Nápoles, y principalmente Venecia, Milán y Florencia. Me refiero a la actividad manufacturera, portuaria, mercantil y bancaria, cuya consecuencia fue el desarrollo de las profesiones jurídicas: los notari (notarios o abogados). Se podría decir que, en cierta medida, la Verdad revelada de la Biblia se fue sustituyendo por la verdad contratada y documentada; así nació la diplomática. El desprestigio correlativo de los teólogos y, más aún, el de los monjes (tenían fama de ignorancia y costumbres relajadas), abrió camino a una profunda transformación social y ética: se impuso un cambio de valores. Sobre la beatitud eterna que prometen la fe y la virtud, empezó a prevalecer la felicidad terrenal que proporciona el dinero. Los humanistas en general, y en especial Erasmo, se beneficiaron del mecenazgo igual que los artistas, casi lo inventaron... Otra novedad fue que los "gramáticos" se atrevieron a criticar la decadente dialéctica aristotélica (barbara et baralipton) practicada en las facultades de teología. Apareció una minoría de gran futuro, los letterati u hombres de pluma, o si se prefiere escritores profesionales. Ser culto (se decía en castellano "leído") se convirtió en un valor social. Dos 
fenómenos de carácter material agilizaron este proceso: los emigrados bizantinos (y los viajeros italianos) trajeron, y vendieron, miles de manuscritos helenísticos, que permitieron volver a las fuentes griegas originarias, fenómeno conocido en Italia como la Scoperta (el Descubrimiento). El ejemplo más espectacular fue la donación por el cardenal Bessarion de 750 códices a la Serenísima República de Venecia, en 1468 que constituyó el fondo primitivo de la Biblioteca Marciana o de San Marcos. La misma Escritura santa fue revisada y la Vulgata latina desplazada por la Biblia griega de los Setenta. La coincidencia de la conquista cultural de Italia por maestros griegos, con la rápida expansión de la imprenta de caracteres móviles, fue un factor determinante de la revolución humanística. Los emigrantes bizantinos que, con sus conferencias suscitaron el entusiasmo por su lengua y cultura, primero en Italia, y posteriormente en la Europa transalpina, fueron unos "comunicadores" excepcionales. Todo empezó con el Concilio ecuménico de Florencia (1438), en el que se intentó reconciliar la confesión católica romana con la ortodoxa griega: vino el patriarca de Constantinopla con una delegación de teólogos. Uno de ellos, Bessarion, se convirtió al catolicismo y se quedó en Italia; posteriormente fue nombrado Cardenal. Los nombres de los pioneros no dejan duda respecto de su origen: Bessarion, Chrysoloras, Calcondilas, Teodoro de Gaza, Argyropulos, Giorgio de Trapisonda, Marco Musuro, Janis Lascaris. Venecia ha sido la puerta de entrada, a partir de Filelfo (Secretario del cónsul veneciano de Constantinopla), y del primer centro impresor de manuscritos griegos, por Aldo Manucio. Pero Florencia ha sido el foco más significativo de platonismo en Italia, gracias al mecenazgo de Medici el Magnífico. Las guerras llevadas en Italia por franceses y españoles fueron para estos "bárbaros" (según los calificaron los italianos) la revelación de la belleza arquitectónica y artística: llevaron a su país no sólo obras de arte y manuscritos, sino artistas (los castillos del Loira son en Francia el glorioso testimonio de este fenómeno) y humanistas (las primeras historias modernas de España y América, Francia, Inglaterra, Hungría se deben a plumas italianas). Tampoco se debe menospreciar el prestigio de la dolce vita, una explosión vital después de terminar la peste negra (a mediados del siglo XIV); un fenómeno en los antípodas del ascetismo 
cristiano, característico de los siglos de fe. Al desprecio del cuerpo humano, repugnante envoltorio del alma inmortal, sucedió el culto a la desnudez y la belleza física, inmortalizada por escultores de la antigua Grecia, como Praxíteles, emulados por artistas italianos como Benvenuto Cellini, Miguel Ángel y Sandro Botticelli. El surgimiento y la expansión del Humanismo coincidieron con el Renacimiento propiamente dicho: renacimiento de los cánones arquitectónicos del clasicismo antiguo; fue la sustitución de la columna corintia y el templo griego por la bóveda gótica ojival y la desnudez de la arquitectura cisterciense. Con el descubrimiento coetáneo de la perspectiva en la pintura, se produjo una doble revolución estética. Tampoco se puede desconocer el efecto considerable de progresos técnicos, en lo civil y en lo militar; también en estos campos los italianos llevaron la voz cantante, basta citar a Leonardo da Vinci y a Cardano. En siglos posteriores, los historiadores han calificado como Renacimiento las diversas expresiones, culturales y artísticas de este período. Ha corrido pareja la promoción social, económica y de prestigio de los "gramáticos" y los artistas (que se distinguieron de los artesanos).

Concomitante con estos fenómenos, la corriente humanista, caracterizada por su helenismo, ofrece, como vamos a ver, un carácter sui generis.

12 Desde los Padres de la Iglesia hasta la revolución humanística, hubo exégetas de la Biblia que acudieron a diversos métodos, como opciones de la hermenéutica: la exégesis literal, la alegórica y la tropológica. Fueron intérpretes de la palabra de Dios en los Evangelios, pero según ya señaló Renan a finales del siglo XIX, no eran filólogos. Con los humanistas aparece la crítica filológica, cuya fuerza subversiva se reveló pronto; esta innovación lleva un nombre, Lorenzo Valla. El romano Valla fue el primero en tener la audacia de aplicar, ya en 1440, la crítica textual a un documento canónico de la Iglesia, la Donación de Constantino. Esto fue abrir una brecha por la que posteriormente irrumpieron, primero Erasmo con su edición del Nuevo Testamento (Novum Instrumentum, 1516), y después Lutero con su Biblia traducida al alemán (1534). Se produjo también una explosión del esoterismo ecuménico contra la fe racionalizada (San Anselmo, Santo Tomás de Aquino): me refiero a la Cábala, judaica y cristiana, el sincretismo ecuménico de Pico 
de la Mirandola. El clima esotérico difundido en toda la Europa continental prosperó singularmente en Inglaterra bajo el reinado de Isabel I, con una figura como Agrippa de Nettelsheim. Es un hecho muy notable, que la Reforma católica (o Contrarreforma), que entró en vigor como efecto de las resoluciones finales del Concilio de Trento (1563), estuviera dirigida tanto contra las corrientes esotéricas del humanismo como contra la Reforma luterana y otras sectas protestantes. Se reprochaba a los humanistas su evangelismo, su filiación con autores sospechosos como Hermes Trismegisto, su real o supuesta homosexualidad, su espíritu de libre examen de las sagradas letras y su devoción por autores antiguos, si bien clásicos no menos "paganos". Las humanidades que se impusieron más tarde como canon de la secundaria incluían a Cicerón, Horacio y Tito Livio, y los más famosos griegos, del siglo de Pericles en particular, Demóstenes y Tucídides, en sus lenguas originales. Esta supervivencia de las humanidades clásicas, el aprendizaje del latín y el griego, se debió sobre todo a la habilidad de los jesuitas, que en sus colegios sometieron a escrutinio la lista de autores y seleccionaron o expurgaron los textos de estudio. En rigor, se salvaron el latín y el griego, y la retórica, pero se vaciaron los textos de la savia que había nutrido al humanismo como movimiento de libertad intelectual.

Una serie de publicaciones ilustra esta libertad: los Comentarios de la lengua griega de Guillaume Budé (1529); el Diccionario políglota de Konrad Gesner (1537); el Léxico grecolatino de Adriaen de Jonghe (1548); la Biblia políglota de Amberes, de Benito Arias Montano (15681573). Entre 1396, fecha en que Manuel Crisoloras inauguró en Venecia la primera cátedra de griego de Italia, y 1540, Adriaen de Jonghe estrenó la cátedra de griego de la Universidad de Leiden, se habían creado doce cátedras universitarias de griego, principalmente en Alemania. En cada reino europeo hubo afamados helenistas; en España y Portugal: Antonio de Nebrija (o Lebrija), el Comendador griego (Hernán Nuñez), Martín de Viciana, Pedro Simón Abril; en Alemania: Reuchlin, Gesner, Celtis, Wolff, Münster; en Francia: Budé, Turnèbe, Casaubon, Amyot; en Inglaterra: Linacre, Colet, Tomás Moro; en Flandes: Erasmo y el sefardí valenciano Vives. Ya en 1523, Guarino de Favorino publicó un Thesaurus universae linguae graecae. Ahora la "grecomania" no dejó de suscitar 
resistencias: en Inglaterra el preceptor de la reina denunció la corrupción de la vida del estilo griego e italiano. Corría un dicho: Inglese italianato é un diávolo incarnato. Varios de estos sabios helenistas fueron también hebraístas, como Reuchlin, cuyo tratado Los rudimentos del hebreo (De rudimentis hebraicis, 1506) suscitó polémica con los dominicos de Augsburgo y persecución inquisitorial contra el autor, sospechoso de criptojudaísmo.

Con un afán proselitista extraordinario, los humanistas fundaron, primero en Italia, colegios (escuelas primarias) para compartir su credo con nuevas generaciones. Los primeros nacieron gracias al mecenazgo de la nobleza, como los Medici, los De Este, el príncipe de Carpi; después hubo otros colegios municipales. El carácter común de estos colegios, como el que dirigió el pionero Vittorino da Feltre en Mantua, conocido como la "Casa Giocosa" (ya en 1423, al amparo de los marqueses de Gonzaga), era su carácter festivo y laico, en un tiempo en que la docencia era monopolio eclesiástico y la disciplina férrea. También se debieron al mecenazgo las primeras ediciones de manuscritos griegos y latinos rescatados del ya desaparecido imperio bizantino (el banquero Chigi tuvo una imprenta en su propia casa de Roma, que hoy es palacio de gobierno de Italia). Pero varios papas, en particular Sixto IV y León X, crearon y desarrollaron la Biblioteca Vaticana, preservando insuperables fondos griegos, hebreos y árabes. Lo propio hizo en Venecia el embajador del emperador, el polígrafo y coleccionista Diego Hurtado de Mendoza. El activo primer prefecto de la Vaticana fue el humanista Bartolomeo Platina (nombrado en 1477); de forma general, los papas favorecieron el ascenso de los humanistas en la jerarquía eclesiástica. Con la infiltración de la Iglesia, éstos se convirtieron en los actores del primer "aggiornamento" (puesta al día) espiritual de la Santa Sede. Evolución que no pudo dejar de suscitar reacciones fundamentalistas entre algunos monjes, como la persecución perpetrada por Savonarola y sus seguidores contra los artistas y los humanistas de Florencia.

La pasión coleccionista por las obras de arte, los manuscritos antiguos y la bibliofilia nació entonces, impulsada por reales ejemplos como Francisco I de Francia, precedido por las familias principescas italianas. Tal pasión se convirtió en criterio de estatus social, como lo sigue siendo 
hoy: los Medici, los Pitti y los Fugger, que originariamente no eran nobles, sino banqueros burgueses, han sido de los más famosos amateurs de su tiempo. El francés Jean Grolier, intendente de las armadas reales, memorable bibliófilo, fue el mayor cliente y mecenas del editor de libros griegos de Venecia, Aldo Manucio. La imprenta, inventada en Estrasburgo y desarrollada en Augsburgo (Gutemberg, Koberger) en la segunda mitad del siglo XV, tuvo una verdadera explosión en los primeros decenios del siglo XVI, primero en Venecia y en varias ciudades germánicas, después en Lyon, París y Basilea (con Froben y Petrina), y en Amberes (con Plantin antes de Elzevir). Fue famosa, primero en Lyon, después en París y finalmente en Ginebra, la editora de libros griegos de la familia Estienne. España y Portugal, donde los incunables fueron obra de judíos, sufrieron la expulsión de los sefardís; con todo, inmigrantes germánicos y franceses desarrollaron la imprenta (importante fue también la editorial sevillana de Jacob Cromberger). Si bien España se quedó atrás en la producción editorial, sus ferias de libros de Medina del Campo fueron comparables con las de Frankfurt y Lyon. Así, se ve cómo una invención técnica de un orfebre alemán provocó una "burbuja económica" en toda Europa; en España, principalmente en Barcelona, Valencia, Zaragoza y Salamanca. También hubo esporádicas ediciones humanísticas en Polonia, Inglaterra, Escandinavia y notablemente en Hungría (gracias al rey Corvino y su esposa Beatriz de Aragón). Con toda razón se ha calificado a la modernidad (hasta la actual revolución informática y digital), como "la civilización del libro", si bien fuera más exacto decir "del impreso". Y es probable que sin el descubrimiento y la expansión de la imprenta (en la primera mitad el siglo XVI), el movimiento humanístico no hubiera trascendido mucho más allá del círculo de los happy few.

Queda que la expresión más acabada del ideal humanista, tanto en el aspecto filológico como en el espiritual, ha sido la creación de colegios trilingües, en una serie sucesiva de ciudades europeas con universidad. Los colegios humanísticos mayores fueron autónomos en general, si bien varios de ellos tuvieron estrecha relación con una universidad; este último caso ha sido el de San Jerónimo, de Alcalá de Henares. Su finalidad fue inseparable del gran diseño del cardenal Jiménez de Cisneros, de publicar una Biblia políglota (obra conocida en la 
historia como "la Políglota de Alcalá" (1520). Hoy día, en México cuando un colegio se llama trilingüe se entiende: inglés, francés y alemán. Pero en la Cristiandad del siglo XVI se trataba de las tres lenguas de la Escritura: latín, griego y hebreo. El latín era el idioma de la Vulgata, versión canónica de la Iglesia romana, la de San Jerónimo; el griego corresponde con la versión conocida como "de los Setenta", otros tantos traductores que coincidieron prodigiosamente; el hebreo era la versión judaica primitiva, desde Moisés. Así que el trilingüismo, más allá de una exploración filológica de las Sagradas Letras, fue una profundización de carácter teológico. Este ha sido uno de los puntos de fricción entre "gramáticos" y teólogos; estos últimos gozaban del exclusivo privilegio de "leer" (interpretar y comentar) la Biblia, y su Biblia era la Vulgata; eran ignorantes del griego y del hebreo; y su latín solía ser el de las fórmulas. Muchas universidades de Europa eran "pontificias" (o reales y pontificias) y destinadas prioritariamente a la formación de teólogos. La creación de colegios trilingües, con el patrocinio de los reyes, y en casos de papas modernistas, consagró el triunfo de la ideología humanista.

Históricamente, el primer intento de enseñanza de las lenguas semíticas a los misioneros católicos del Medio Oriente se debió a Ramón Llull en su Colegio de Miramar. Después, intentó convencer a las autoridades de la Sorbona, pero no lo consiguió. El obstinado religioso logró por fin un decreto del papa Juan XXII, de 1317, ordenando crear cátedras de griego, caldeo, hebreo y árabe, en las pontificias universidades de Roma, Bolonia, París, Oxford y Salamanca. Quedó por lo general en letra muerta hasta que el papa humanista León X decidiera crear el Colegio romano de jóvenes griegos, en 1515. Otro precursor fue el obispo de Tebas, Simón Atumanos, con su Biblia triglota, manuscrita, ya en 1381. Tales antecedentes revelan que el humanismo no surgió de la nada, ni bruscamente: fue más bien la ampliación o hasta explosión a plena luz de unas corrientes de renovación espiritual que se venían gestando desde principios del siglo XIV. Sobre el trilingüismo, sentenció Erasmo que se trataba de "tres lenguas sin las cuales todo el sistema educativo queda manco" (1519). Erasmo fue educado en este clima por los religiosos agustinos de Deventer en Flandes. Es ilustrativa de la expansión del 
humanismo la cronología de fundación de los colegios trilingües. En 1515 Richard Fox funda el Colegio de Corpus Christi, de Oxford. En 1517 Busleiden (siguiendo la sugerencia de Erasmo) crea el Colegio trilingüe de Lovaina. En 1519, el emperador Maximiliano planea la creación de un colegio trilingüe en Augsburgo, bajo la dirección de Lefèvre d'Etaples (falleció el soberano y el proyecto se abandonó). En 1528 (o 1529 según otros), el cardenal Jiménez crea el Colegio trilingüe de San Jerónimo, de Alcalá. Puntualiza Bataillon que, en este último, se dieron doce becas para retórica, doce para griego y seis para hebreo. En 1531, el rey Francisco I de Francia, inspirado por Guillaume Budé, crea el Colegio de los lectores reales (con dos de griego y dos de hebreo). En 1544 la duquesa de Calabria firma un convenio con la universidad de Valencia, para crear un colegio trilingüe (su muerte impidió la realización). En 1552, finalmente, la tradicionalista universidad de Salamanca, bastión del tomismo, cede a la presión del emperador Carlos V (fiel a la memoria de Erasmo) y establece su propio colegio trilingüe. Si se piensa bien, los colegios trilingües fueron el detonador de una revisión exegética y una secesión dogmática, del evangelismo al luteranismo. Esto demuestra que en la civilización del Libro (la Biblia), gracias también a la difusión de los libros que hoy llamamos "clásicos", la filología (que se decía "gramática") ha hecho una revolución cultural tan trascendente como fueron en la misma época el uso de la artillería en la guerra, los viajes de Colón y Vasco de Gama en la geografía, y los cálculos de Kepler y Galileo en la cosmología.

El Humanismo no es sólo un ente de razón forjado por historiadores modernos, sino fundamentalmente una cofradía informal de hombres unidos por el amor a la lengua y la filosofía griega antigua. Hubo relativamente pocas mujeres; éstas fueron grandes privilegiadas, como Beatriz de Luna (Gracia Mendes Nasci), Mencía de Mendoza o Margarita de Navarra. Su figura tutelar era Platón; la elección de Platón fue un desafío a Aristóteles, llamado por los escolásticos el Filósofo (Philosophus). Llegaron a dar la bienvenida con la fórmula "amados en Platón" (en lugar de la expresión tradicional "amados en Cristo") y a celebrar ritos del politeísmo griego antiguo. De Platón heredaron el diálogo como método pedagógico (mayéutica), sustituto de la lección magistral 
tradicional (un profesor era un "lector”). Pero los más difundidos diálogos fueron los festivos Coloquios (Colloquia) de Erasmo (1517), precedidos en su obra por los no menos famosos Adagios. Estas obras de Erasmo, así como este género literario, en boga en aquel tiempo, se inspiraron en los diálogos satíricos del sofista griego Luciano de Samosata. El mismo Erasmo, en colaboración con Tomás Moro, había publicado pocos años antes una traducción al latín de los diálogos de Luciano. Posteriormente, el autor de Gargantúa y Pantagruel, el médico Rabelais, fue apodado "el Luciano francés": era capaz de escribir poesías en griego. Hubo gran variedad de temas de diálogos para satisfacer la curiosidad de todo público: Diálogo de la montería de Luis Barahona de Soto; Diálogo entre el amor y un viejo de Rodrigo Cota; Diálogo de un cazador y un pescador de Fernando Basurto; Disputa de locura y amor (Le débat de Folie et d'Amour) de la poetisa Louise Labé; hasta el Diálogo que pasó entre Cipión y Berganza, perros del Hospital de la Resurrección [...] de Valladolid, escrito tardío en veta lucianesca, obra de Cervantes. Por no abultar esta enumeración, mencionemos El cortesano (Il cortigiano, 1528) de Baltazar Castiglione, obra de encargo del rey Francisco I de Francia, que ha sido el best seller internacional del género. En español descuellan el del erasmista Alfonso de Valdés, Diálogo de Mercurio y Carón (1529) y El Crótalon de Cristóbal de Villalón ( $c a$. 1553). Además, la forma dialogada ha sido objeto de tratados didácticos de varios autores, primero italianos, como Sperone Speroni, Diálogos (Dialogi, 1542), Carlo Sigonio, De dialogo liber (1562), y tardíamente, Torcuato Tasso, Dell'arte del dialogo (1587).

De forma general, la literatura humanística se caracteriza por la abundancia de libros manuales de distintas disciplinas y géneros literarios: la poesía, el arte dramático, y singularmente la historiografía. ${ }^{1}$ El primero de historiografía es de Bartolomeo della Fonte, de 1482; entre esta fecha y el final del siglo XVI, se publicaron en diversos idiomas (sobre todo en latín), 47 tratados sobre "Cómo escribir" o pautar, o leer, la historia; el de mayor difusión y prestigio fue el extenso manual de Jean Bodin, Methodus ad facilem historiarum cognitionem, que tuvo,

${ }^{1}$ Véase mi De la historia biblica a la historia crítica, 2013, México, FCE. 
entre 1566 y 1610, cinco reediciones, en París, Lyon, Estrasburgo, Basilea y Ginebra.

Lo que unía a los humanistas fue también la pasión común por los manuscritos antiguos y sus primeras ediciones: enumerarlas sería cuento de nunca acabar. Al contrario, lo que los dividía era la rivalidad en la aspiración a la fama y las prebendas. Hubo sañudas riñas, como la que opuso el romano Lorenzo Valla al florentino Poggio Bracciolini; las más vivas fueron entre la docena de maestros griegos (bizantinos) de los principados italianos. Los humanistas consagrados viajaban por toda Europa y cambiaban cartas (en latín o griego), libros y manuscritos; se reunían en círculos llamados "academias", remedo de la Academia ateniense de Platón. La primera fue la Academia platónica de Marsilio Ficino que, bajo el patrocinio de Lorenzo de Médici, se reunía en la villa de Careggi; también fueron famosas la de Giovanni Pontano en Nápoles, la de Pomponio Leto en Roma, la de Aldo Manucio en Venecia, las "Cámaras de retórica", asociadas con los juegos florales de Flandes, las "Sociedades de cámara" de Estrasburgo y la de Sélestat animada por Beatus Rhenanus (celebrada en versos latinos por Erasmo). Hay que reconocer (para no caer en simplificaciones) que hubo entre los humanistas, sabios de gabinete como Erasmo, profesores itinerantes como los griegos, sospechosos de luteranismo como el portugués Damiao de Gois, prelados como Eneas Silvio Piccolomini, estadistas como Guillaume Budé, hasta aventureros como el veneciano Filelfo, el germano Ulrich von Hutten, y en cierto sentido, el cosmopolita George Buchanan.

Si bien el griego clásico fue la pasión de todos aquellos hombres, sería imposible hacer caso omiso de su lengua vehicular: el latín clásico, que fue la otra cara de la Scoperta. En efecto, se descubrieron manuscritos de importancia determinante como la Retórica a Herenio y las Cartas familiares y varios discursos o alegatos de Cicerón. El latín de la República y el Imperio de Augusto revivió tanto como el griego de Demóstenes. La imitación de Tulio, conocida como el "ciceronianismo" y la consiguiente disputa en pro y en contra del orador, da la medida de la importancia del latín clásico redivivo. Lo mismo revela la controversia entre los imitadores de Tito Livio y los adictos a Tácito, como 
Justo Lipsio, su principal apologista. El latín, lejos de ser lengua muerta, estuvo muy vivo, como atestigua la correspondencia de los humanistas. ¿Quién se acuerda hoy de que se publicaron docenas de tomos de cartas supuestamente "familiares", pero en realidad destinadas a ser publicadas? Imitación de las del Arpinate fueron las de Petrarca, de Erasmo, de Justo Lipsio, quien publicó un método epistolario titulado Epistolica institutio (1591). El récord lo tuvo el cardenal Sadoleto, cuya edición por el impresor Grifo, de Lyon, alcanzó los 16 libros. De Melanchton, el definidor de la confesión reformada y gran políglota, quedaron miles de cartas. Todo este acervo de literatura epistolar en latín es reflejo de lo que fue, como fenómeno cultural, religioso y político, el humanismo renacentista: estas cartas fueron la gaceta de su tiempo.

También se publicaron pletóricos libros de emblemas; el más conocido en español es Emblemas morales de Sebastián de Covarrubias, pero se trata de una obra tardía en el género, puesto que salió en 1612. La obra más difundida y de mayor influencia de este género ha sido el libro de emblemas ("epigramáticos" según el autor) de Alciato, titulado Emblematum liber, publicado originalmente en Augsburgo en 1531, reeditado en París, Lyon, Venecia: hubo en total 120 ediciones entre el siglo XVI y el XVII. Tuvo gran éxito y traducciones el libro de emblemas (también en latín) del eslovaco Sambucus (Janos Zsamboky), que publicó en 1564 Christophe Plantin, en Amberes. Pero el latín no era sólo lengua escrita, sino hablada en la sede apostólica romana (a diferencia de la liturgia ortodoxa griega), las relaciones internacionales y las universidades en que los cursos se impartían casi siempre en dicha lengua. La mayoría de las obras maestras del siglo XVI fueron escritas y publicadas primero en latín: las Décadas del Nuevo Mundo, de Pietro Mártir, los Adagios y el Elogio de la locura, de Erasmo, la Utopía de Tomás Moro, la Historia de España del padre Mariana y un largo etcétera de obras de historia. ¿Quién se fija ahora en que grandes poetas como Petrarca, Du Bellay, Milton escribieron más versos en latín que en toscano, francés, o inglés?

Otro aspecto del humanismo, en apariencia contradictorio, ha sido la consagración de las lenguas vulgares (o en la jerga vaticana, "vernáculas"). 
La creación por el arzobispo Federico Borromeo -junto con la Biblioteca ambrosiana (1607) - de un colegio trilingüe en Milán, en que las tres lenguas enseñadas fueron latín, griego e italiano (esto es, toscano), sella la evolución del trilingüísmo hacia la Modernidad. En efecto, junto a sus aspectos cosmopolitas y su culto a la Antigüedad, los humanistas fomentaron el patriotismo cultural y lingüístico, expresado primero por historiadores: como en Italia, Flavio Biondo; en Francia, Etienne Pasquier; en Alemania, Conrad Celtis; en Inglaterra, Leland, y en Escocia Buchanan. A pesar del dominio cultural del latín y el griego, característico del movimiento humanista, las lenguas vulgares se fueron imponiendo progresivamente como instrumento literario. Su léxico y su gramática se ordenaron a imitación de las lenguas antiguas. Ya en 1533, Charles de Bovelle publicó en latín Liber de differentia vulgarium linguarum (Libro de la diferencia de las lenguas vulgares). Casi simultáneamente, el fecundo polígrafo Leon Battista Alberti publicó la Grammatica della volgare lingua, en este caso el toscano que, por el prestigio de Dante y Petrarca, se convertiría en lengua oficial de toda Italia. En España, Juan de Valdés publicó su Diálogo de la lengua en 1535; en 1541 salió una Retórica en lengua castellana, atribuida a Miguel de Salinas; como se sabe, la famosa Gramática de Nebrija fue escrita ya en el año del "Descubrimiento" del Nuevo Mundo. En Francia, el poeta Joaquin Du Bellay dio a la luz pública (en 1549) un programa lingüístico y literario del romance francés, titulado elocuentemente, Défense et illustration de la langue française (Apología e ilustración de la lengua francesa). En Alemania la traducción de la Biblia al alemán por Martín Lutero y sus consignas a los príncipes y las ciudades, en 1524 y 1530, instándoles a crear escuelas públicas para que todos los niños aprendan el catecismo reformado en su lengua materna, fue como el acto de nacimiento del Hochdeutsch o lengua oficial del imperio. Parecido fenómeno ocurrió más tarde en Inglaterra con la traducción a lengua vulgar de la Biblia conocida como King's James Bible, de 1611. De estas observaciones se puede concluir que, lejos de retrasar el surgimiento de literaturas en lenguas vulgares, el cultivo del latín y el griego antiguos lo han favorecido. El humanismo ha sido fundamentalmente un inmenso taller 
de traducción y los humanistas una asociación cosmopolita de traductores. Fijarse bien en que, hasta cuando menos el siglo XVIII, el latín se usó como lengua filosófica y científica internacional: Descartes, Leibniz, Spinoza, Hobbes, escribieron en latín, hasta que se impuso el francés como lingua franca del Siglo de las Luces; Alejandro de Humboldt publicó originalmente en esta lengua el Essai politique sur le royaume de la Nouvelle-Espagne (1811).

Las humanidades clásicas sobrevivieron hasta el siglo XX como la espina dorsal del sistema educativo de Europa (y sus imitadores americanos). Bergson y Jaurés presentaron tesis latinas en la Sorbona, y así se hizo hasta la Primera guerra mundial. Hasta hoy en Leiden (plaza reformada) y en la Gregoriana de Roma (universidad pontificia) se defienden los doctorados en latín. Ahora, aproximadamente desde 1968 y sus secuelas, han desaparecido las humanidades clásicas de las secundarias: el griego clásico ha pasado a ser "lengua rara" y el poquísimo latín que todavía se enseña está relegado a opción de fin de cursus: una "lengua muerta". ¿Es la muerte del humanismo?

La pregunta es recurrente, dado que los maestros de mi generación ya nos veían como humanistas degenerados en comparación de la formación que ellos mismos habían recibido. El asunto de la muerte del humanismo es algo parecido al Monstruo del Loch Ness, que se sumerge y vuelve a asomarse en fechas inesperadas. Los historiadores modernos han diagnosticado una "primera muerte" del Humanismo ya en 1494, cuando el rey Carlos VIII de Francia invadió Italia para conquistar Nápoles. Aquel mismo año murió en Florencia Lorenzo de Médici, padre tutelar de los artistas y los primeros grandes filósofos humanistas: Pico de la Mirandola y su amigo Angelo Poliziano. También se ha visto el saqueo de Roma por la soldadesca imperial, en 1527, como "la segunda muerte" del humanismo; desaparecieron manuscritos, bibliotecas, se dispersaron los sabios y se desvaneció el clima humanístico que prevalecía en la curia pontificia. Otros ven la fecha de 1536 como "la tercera muerte" del humanismo por el fallecimiento de Erasmo, cuya influencia en vida fue inmensa, de España a Polonia, pero cuyas obras iban a ser inscritas en el índice romano de libros prohibidos. El mismo año 
murió el padre del evangelismo, Lefèvre d'Etaples, otra figura señera de un humanismo cristiano al que se reprochaba haber abierto el camino a Lutero.

Para tener una apreciación equilibrada del humanismo se ha de recalcar que ha sido la confluencia de fenómenos culturales que se iniciaron a mediados del siglo XIV, llegaron a su auge en los primeros decenios del siglo XVI y tuvieron su ocaso a principios del siglo XVII. Ya hemos rebasado la fecha de la muerte de las humanidades, legado humanista que formó parte del nivel medio del cursus escolar, entre el siglo XVI y el XX. El estado de la sociedad y los criterios de evaluación y rendimiento que hoy en día prevalecen en las reformas del sistema educativo, en todo el mundo, no permiten pensar que las humanidades vayan a resucitar. Esto es altamente deplorable: más allá de "la inutilidad" supuesta de las humanidades está el ideal de la Grecia antigua de crear ciudadanos libres, cultos y atléticos, que no por supuesto empleados de empresas multinacionales y consumidores de indigentes programas de cine y televisión "global". Cuando le di título a mi último libro publicado: Un humanista del siglo XX, Marcel Bataillon (2014, FCE), no quise consumar la segunda muerte de mi amado maestro, sino proponer a nuevas generaciones el ejemplo de aquel gran erasmista y humanista. El humanismo no ha sido una doctrina, sino una dinámica y una esperanza; una fuerza espiritual independiente de y superior a los programas educativos. Ser humanista hoy es dar la prioridad al capital humano sobre el capital financiero, y al medio natural sobre las necesidades artificiales. Mientras siga viva la aspiración a la plenitud de humanidad no morirá el Humanismo.

He dicho.

Guadalajara, julio 2014. 


\section{Bibliografía indicativa en español}

BARÓN, Hans, En busca del humanismo cívico florentino, 1993, México, FCE. BAtAillon, Marcel, Erasmo y España, 1950, México, FCE, trad. de Antonio Alatorre (con varias reediciones). co Rico.

BAtLlORI, Miquel, Humanismo y Renacimiento, 1987, Barcelona, Ariel.

BAXANDALl, Michael, Giotto y los oradores, 1996, Madrid, Visor.

Bouwsma, William J., El otoño del Renacimiento, 1550-1640, 2001, Barcelona, Crítica.

BURCKHARDT, Jacob, La cultura del Renacimiento en Italia, 1968, Barcelona, Zeus.

BURKE, Peter, Los avatares de El cortesano, 1995, Barcelona, Gedisa.

CASSIN, Barbara (ed.), Nuestros griegos y sus modernos, 1994, Buenos Aires, Manantial.

Castiglione, Baltasar de, El Cortesano, 1997, México, unAm (Nuestros Clásicos, 78).

COVARRUBiAs OROZCO, Sebastián de, Emblemas morales, 1610, Madrid, Luis

Sánchez (ed. facsímil, 1978, Madrid, Fundación Universitaria Española).

CHABOD, Federico, Escritos sobre el Renacimiento, 1990, México, FCE.

CHASTEl, André, El humanismo, 1971, Barcelona, Salvat.

24 CHeVALIER, Maxime, Lectura y lectores en la España del siglo XVI y XVII, 1976, Madrid, Turner.

DeBUS, Allen G., El hombre y la naturaleza en el Renacimiento, 1985, México, FCE (Breviarios, 384).

Delgado CaSAdo, Juan, Diccionario de impresores españoles (siglos XV a XVII), 1996, Madrid, Arco/Libros, 2 vols.

DomíngUEZ, Juan Francisco (ed.), Diccionario biográfico y bibliográfico del humanismo español (siglos XV-XVII), 2012, Madrid, Ediciones clásicas.

DOMínguez CAPARRós, José, Orígenes del discurso crítico, 1993, Madrid, Gredos.

ERASMO DE RotTERDAM, Elogio de la locura, 2000, México, UNAM (Nuestros clásicos, 90). , Educación del príncipe cristiano, 1996, Madrid, Tecnos.

EsteBAn, Mateo L., Martín R. López y Juan L. Vives, La escuela de primeras letras según Juan Luis Vives, 1993, Valencia, Universidad de Valencia. 
Gil Fernández, Luis, Panorama social del humanismo español, 1997, Madrid, Tecnos.

GARCÍA YEBRA, Valentín, Traducción: Historia y teoría, 1994, Madrid, Gredos. GARCILASO DE LA VeGA, Obra completa, 2004, Madrid, Edaf.

KRISTELler, Paul Oskar, Ocho filósofos del Renacimiento italiano, 1970, México, FCE (Breviarios, 210).

LAFAYE, Jacques, Un humanista del siglo XX, Marcel Bataillon, 2014, MéxiCO, FCE.

, De la historia bíblica a la historia crítica, 2013, México, FCE. , Por amor al griego, 2005, México, FCE. Albores de la imprenta, 2002, México, FCE.

Sangrientas fiestas del Renacimiento, 1999, México, FCE (Breviarios, 534).

Maquiavelo, Nicolás, El Príncipe, 1994, México, Gernika.

MARTín RodríGuEZ, Antonio María y Germán Santana Henríquez (eds.), El humanismo español, su proyección en América y Canarias en la época del humanismo, 2006, Gran Canaria, Universidad de Las Palmas.

NicCOLI, Ottavia (ed.), La mujer del Renacimiento, 1993, Madrid, Alianza.

PELIGER, Juan Vicente, Formulario y estilo curioso de escrivir cartas missivas, 1599, Madrid, Pedro Madrigal (ed. facsímil, Valencia, 1993).

PiCo Della Mirandola, Giovanni, Discurso sobre la dignidad del hombre, 2003, UNAM (Pequeños grandes ensayos, 5), trad. de Adolfo Ruiz D.

PlutARCo, Acerca del Destino, 1996, México, unAM, Biblioteca Scriptorum Graecorum et Romanorum Mexicana, trad. de Pedro C. Tapia Zúñiga y Martha Bojórquez.

RALlO GRUSS, Asunción, La escritura dialéctica: estudios sobre el diálogo renacentista, 1996, Málaga, Universidad de Málaga.

Rico, Francisco, El sueño del humanismo. De Petrarca a Erasmo, 2002, Barcelona, Destino.

Rojas GARCIDUeÑas, José (ed.), Autos y coloquios del siglo XVI, 1989, México, UNAM.

SANTIDRIÁN, Pedro R. (ed.), Humanismo y Renacimiento (antología), 1986, Madrid, Alianza.

SymondS, John A., La cultura del Renacimiento en Italia, 1957, México, FCE, 2 vols.

TorquemadA, Antonio de, Manual de escribientes, 1970, Madrid, Anejos del Boletín de la Real Academia Española, ed. de María Josefa Canellada y Alonso Zamora Vicente. 
VALDÉS, Alfonso de, Diálogo de las cosas acaecidas en Roma, 1992, Madrid, Cátedra.

VERNET, Juan, Astrología y astronomía en el Renacimiento, 2000, Barcelona, El Acantilado.

VIVES, Juan Luis, El arte retórica. De ratione dicendi, 1998, Barcelona, Anthropos.

WITKOWER, Rudolf, Los fundamentos de la arquitectura en la edad del humanismo, 1995, Madrid, Alianza.

YATES, Frances A., La filosofia oculta en la época isabelina, 1982, México, FCE.

YNDURÁIN, Domingo, Humanismo y Renacimiento en España, 1994, Madrid, Cátedra. 